\title{
動作状態が変化する多入出カシステムの安定化
}

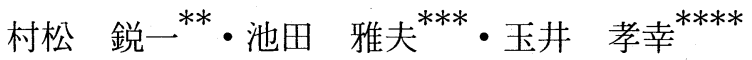

\section{Stabilization of Multi-Input Multi-Output Systems with Variable Operating Conditions*}

\author{
Eiichi Muramatsu**, Masao IKedA ${ }^{* * *}$ and Takayuki Tamai ${ }^{* * * *}$
}

\begin{abstract}
A stabilization problem is considered for linear time-invariant multi-input multioutput systems with variable operating conditions. The plant is assumed to be modeled as an interpolation of two nominal plants described by proper stable factorizations of transfer function matrices. To stabilize the closed-loop system, two kinds of controllers are proposed. One is a fixed controller, and the other is an interpolation of stabilizing controllers for the nominal plants. For each case, sufficient conditions for stabilization are reduced to solvability of certain $H^{\infty}$ control problems. Design algorithms for the proposed controllers are presented in the state space. The relation to the simultaneuos stabilization problem for two nominal plants is also considered.
\end{abstract}

\section{1.はじめに}

この論文では, 動作状態の変化により特性が変化する 多入力多出力の制御対象の安定化問題を考察する. 制御 対象は，代表的な動作状態に拈けるモデル（基準モデル） の補間によって表わすことができるとする.

制御対象の特性変化を補間によって表わす方法には, 参考文献 1)～7）のように種々のものが考えられる. 本 論文では, 参考文献 4)〜7）と同様に，二つの基準モデル の伝達関数行列のプロパかつ安定な既約分解表現に抢け る各分解要素の線形補間を考え, 特性変化を補間パラメ 一タの変化に対応させる. そして, このような制御対象 を安定化するコントローラとして, 次の 2 種類のコント ローラの設計法を示す. 一つは基準モデルの安定化コン トローラを補間したコントローラであり，あう一つは補 間は行わない固定したコントローラである.コントロー ラを補間する目的は, 制御対象の特性変化に対応してコ

* 原稿受付 1993 年 7 月 12 日

** 住友金属工業 Sumitomo Metal Industries, Ltd. ; 1-8 Fuso-cho, Amagasaki city, Hyogo 660, JAPAN

*** 神戸大学 工学部 Faculty of Engineering, Kobe University ; 1-1 Rokkodai-cho, Nada ward, Kobe city, Hyogo 657, JAPAN

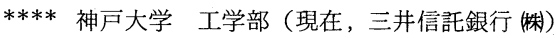

Faculty of Engineering, Kobe University ; ditto

Key Words : variable operating conditions, stabilization, coprime factorization, interpolated plants, interpolated controllers.
ントローラを変更することによって, 安定化可能な制御 対象の範囲をより広くすることである.

このような制御対象とコントローラの設計に関する問 題は, 1 入力 1 出力系について参考文献 3) 7) で考察さ れており，ネバンリナ・ピックの補間問題に帰着させる 手法により, 制御系を安定化するコントローラが存在す るための必要十分条件とコントローラの設計法が得られ ている. しかし多入力多出力系に掠てて, ネバンリナ・ ピックの補間問題に帰着させる手法を適用することがで きず，必要十分条件を得ることは困難である．そこで, 本論文では, 多入力多出力系を安定化するコントローラ が存在するための十分条件を, ある $H^{\infty}$ 制御問題の可 解性に帰着させ, 状態空間表現によるコントローラの設 計法を示す。

なお，筆者らは二つの基準モデルの補間によって表わ される 1 入力 1 出力の制御対象が安定化可能であるため には, 二つの基準モデルが同時安定化可能であることが 必要であることを, 参考文献 6) に拉いて示した. 多入 力多出力系に颃いても同様であるてとを本論文で明らか にする.

本論文の構成は，次のとおりである．2. で制御対象の 記述抢よび問題設定を行い，3. に括いて制御系を安定化 する各コントローラが存在するための十分条件が $H^{\infty}$ 制 御問題の可能性に帰着できることを示す. 4. では $H^{\infty}$ 制御問題の解を用いて, コントローラの設計法を示す.

5. で同時安定化可能性との関連を示す. 


\section{2. 問題設定}

Fig. 1 の多入力多出力の制御系を考える. $G$ は制御対 象, $K$ はコントローラの伝達関数行列を表わす. 制御対 象の伝達関数行列 $G$ は, 二つの基準モデルの伝達関数 行列 $G_{i}(i=1,2)$ のプロパかつ安定な有理関数行列の 集合 (以下, $R H^{\infty}$ と記す) 上の既約分解

$$
\begin{aligned}
G_{i} & =N_{i} D_{i}^{-1} \\
& =\tilde{D}_{i}^{-1} \tilde{N}_{i}
\end{aligned}
$$

を用いて，つぎのように記述されるあのとする.

$$
\begin{aligned}
& G=N D^{-1} \\
& N=\alpha N_{1}+(1-\alpha) N_{2}, \\
& D=\alpha D_{1}+(1-\alpha) D_{2}, \\
& \quad 0 \leq \alpha \leq 1
\end{aligned}
$$

こてで， $\alpha$ は制御対象の動作状態の変化に応じて, 0 から 1 の間を変化するパラメータである. $\alpha=1$ のとき $G=$ $G_{1}, \alpha=0$ のとき $G=G_{2}$ となることは明らかである.

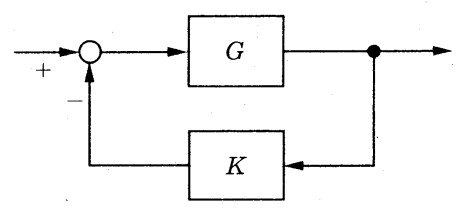

Fig. 1 Closed-Loop system

（注意 1 ） 本論文は, 動作状態の変化が一つのパラメ 一夕による線形補間で正確に表わすことができるという 立場に立つのではなく，補間表現は制御対象を近似する 一つの公称モデルと考えている. 一つのパラメータによ る近似が不充分であれば，二つ以上のパラメータを導入 する必要がある．また，基準モデルの既約分解の選び方 が異なれば，(3)，(4) 式の $G$ は異なる伝達関数行列にな るので, 近似という観点から, 基準モデルの既約分解の 選び方について議論する必要がある. これらについて, 筆者らは，実際問題への応用の観点を含め, 稿を改めて 考察する予定である.

このような制御対象を安定化するとき，パラメータ $\alpha$ の值が利用可能な場合には，それを積極的に利用して次 のような形式のコントローラを設計することが考えられ る.

$$
\begin{aligned}
& K=\tilde{D}_{K}^{-1} \tilde{N}_{K} \\
& \tilde{N}_{K}=\alpha \tilde{N}_{K 1}+(1-\alpha) \tilde{N}_{K 2} \\
& \tilde{D}_{K}=\alpha \tilde{D}_{K 1}+(1-\alpha) \tilde{D}_{K 2}
\end{aligned}
$$

$\alpha=1$ のとき $K=\tilde{D}_{K 1}^{-1} \tilde{N}_{K 1}, \alpha=0$ のとき $K=\tilde{D}_{K 2}^{-1} \tilde{N}_{K 2}$,
であるので,

$$
\begin{aligned}
& K_{1} \triangleq \tilde{D}_{K 1}^{-1} \tilde{N}_{K 1} \\
& K_{2} \triangleq \tilde{D}_{K 2}^{-1} \tilde{N}_{K 2}
\end{aligned}
$$

とすれば,（5),（6）式のコントローラ $K$ は, 制御対象 の変化を表わすパラメータ $\alpha$ にって， $K_{1}$ と $K_{2}$ を補 間したものとなる. これにより, 制御対象の変化に対応 してコントローラあ変化させる制御系が構成される. 乙 のとき, 当然, コントローラ $K_{1}, K_{2}$ はそれぞれ基準モ デル $G_{1}, G_{2}$ を安定化するあのでなければならない.

以上は， $\alpha$ の值が利用できる場合には有効であるが, $\alpha$ の值を利用できない場合には， $\alpha$ に依存しないコント ローラで安定化しなければならない，本論文ではまずて の問題から考察する.

以下，(3)，(4) 式のように記述される制御対象を“補 間制御対象”，(5)，(6) 式のコントローラを“補間コント ローラ”， $\alpha$ に依存しないコントローラを“固定コントロ ーラ”と呼ぶことにする.

ここで，後の式の展開のため, $N_{i}, D_{i}, \tilde{N}_{i}, \tilde{D}_{i}(i=$. 1,2)に対して,

$$
\left[\begin{array}{cc}
Y_{i} & X_{i} \\
-\tilde{N}_{i} & \tilde{D}_{i}
\end{array}\right]\left[\begin{array}{cc}
D_{i} & -\tilde{X}_{i} \\
N_{i} & \tilde{Y}_{i}
\end{array}\right]=\left[\begin{array}{cc}
I & 0 \\
0 & I
\end{array}\right]
$$

が成立するような $X_{i}, Y_{i}, \tilde{X}_{i}, \tilde{Y}_{i} \in R H^{\infty}$ を定義してお く.また, 行列

$$
V=\left[\begin{array}{ll}
V_{11} & V_{12} \\
V_{21} & V_{22}
\end{array}\right]
$$

に対する線形分数变換 DHM を

$$
\operatorname{DHM}(V ; S)=\left(V_{11}+S V_{21}\right)^{-1}\left(V_{12}+S V_{22}\right)
$$

とする. DHM に関して,

$$
\operatorname{DHM}\left\{V_{1} ; \operatorname{DHM}\left(V_{2} ; S\right)\right\}=\operatorname{DHM}\left(V_{2} V_{1} ; S\right)
$$

が成り立つ.プロパかつ安定な有理関数行列で, $H^{\infty}$, ルムが 1 末満のものの集合を $B H^{\infty}$ と記す.

\section{3. 制御系の安定化可能条件}

\section{1 固定コントローラによる安定化}

(3)，(4) 式の補間制御対象 $G$ に対して, コントローラ を $\alpha$ にらず固定とした場合の制御系が安定化可能とな る条件を考察する．補間制御対象を安定化するコントロ 一ラは, $\alpha=1$ のとき,つまり制御対象が $G_{1}$ のとき制御 系を安定化することが必要である. したがって，Fig.1 の制御系を安定化するコントローラを， $G_{1}$ に対する安 定化するコントローラの一般形 


$$
\begin{aligned}
& K=K_{1}=\tilde{D}_{K 1}^{-1} \tilde{N}_{K 1} \\
& \tilde{N}_{K 1}=X_{1}+R_{1} \tilde{D}_{1} \\
& \tilde{D}_{K 1}=Y_{1}-R_{1} \tilde{N}_{1}
\end{aligned}
$$

によって表現しょう.ただし， $R_{1}$ は任意の $R H^{\infty}$ の元 である。

よく知られているように (3) 式の制御対象 $G$ に対し て，(13）式のコントローラにより制御系が安定である ための必要十分条件は,

$$
\Omega_{1} \triangleq \tilde{D}_{K 1} D+\tilde{N}_{K 1} N
$$

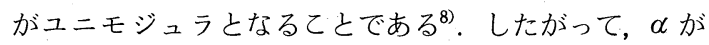
$0 \leq \alpha \leq 1$ のいかなる值をとっても， $\Omega_{1}$ がユニモジュ ラとなるような $R_{1}$ が求められれば，補間制御対象は安 定化可能である.

まず, $\tilde{D}_{K 1}, D, \tilde{N}_{K 1}, N$ に (4), (14) 式を代入し,

（9）式を利用するととにより,

$$
\begin{aligned}
\Omega_{1} & =\alpha I+(1-\alpha) \Phi_{1} \\
& =\{\alpha+(1-\alpha) \beta\} I+(1-\alpha)\left(\Phi_{1}-\beta I\right) \\
& =(1-\alpha)\left\{\frac{\alpha+(1-\alpha) \beta}{1-\alpha} I+\left(\Phi_{1}-\beta I\right)\right\}
\end{aligned}
$$

と計算できる.ただし，

$$
\begin{aligned}
& \Phi_{1}=T_{a 1}-R_{1} T_{b 1} \\
& T_{a 1}=X_{1} N_{2}+Y_{1} D_{2} \\
& T_{b 1}=\tilde{N}_{1} D_{2}-\tilde{D}_{1} N_{2}
\end{aligned}
$$

であり, $\beta$ は任意の正数である.

ここで， $\Omega_{1}$ がユニモジュラとなるための十分条件を つぎの補題を利用して与える.

【補題 $1 】^{8)} M$ をユニモジュラ行列， $S \in R H^{\infty}$ とす る. このとき,

$$
\|S\|_{\infty}<\frac{1}{\left\|M^{-1}\right\|_{\infty}}
$$

であれば, $M+S$ はユニモジュラである.

この補題より,

$$
\left\|\Phi_{1}-\beta I\right\|_{\infty}<\frac{\alpha+(1-\alpha) \beta}{1-\alpha}
$$

であれば， $\Omega_{1}$ がユニモジュラとなる．上式の右辺は $\alpha=0$ のとき最小值 $\beta$ をとるので,

$$
\left\|\Phi_{1}-\beta I\right\|_{\infty}<\beta
$$

であれば $\alpha の$ 値によらず $\Omega_{1}$ がユニモジュラとなる.

したがって, 次の補題が成り立つ.

【補題 2】ある正数 $\beta$ に対して,

$$
\left\|\left(T_{a 1}-\beta I\right)-R_{1} T_{b 1}\right\|_{\infty}<\beta
$$

を満たす $R_{1} \in R H^{\infty}$ が存在すれば，補間制御対象 $G$ を
安定化する固定コントローラ $K$ が存在する.

(22) 式を満たす $R_{1}$ が存在するかどうかという問題 は， $H^{\infty}$ 制御問題として取り扱うことができ，その解を 用いるととにより $R_{1}$ の構成法を得ることができる. 状 態空間での具体的な $R_{1}$ の存在条件とコントローラの設 計法は 4. 亿扔いて述べる.

(注意 2) $\left\|\Phi_{1}-\beta_{1} I\right\|_{\infty}<\beta_{1}$ が成り立つとき，ノル $\Delta$ 性質より $\left\|\Phi_{1}-\left(\beta_{1}+\beta_{2}\right) I\right\|_{\infty} \leq\left\|\Phi_{1}-\beta_{1} I\right\|_{\infty}+\beta_{2}<$ $\beta_{1}+\beta_{2}$ が成り立つ.したがって，(22）式の条件は， $\beta$ を大きく選ぶほど成立しやすい，制御対象が 1 入力 1 出 力の場合，乙の条件を図を用いて表現すると，右閉半平 面の $s$ に対する (16) 式の $\Phi_{1}$ の值が, Fig. 2 の円（中心 $(\beta, 0)$ ，半径 $\beta)$ の内部に入る乙とを意味する. なお， 1 入力 1 出力の制御対象の場合の必要十分条件 ${ }^{6), 7)}$ は, 右 閉半平面の $s$ 亿対する $\Phi_{1}$ の值が原点と負の実軸を除く 領域内に存在することである.

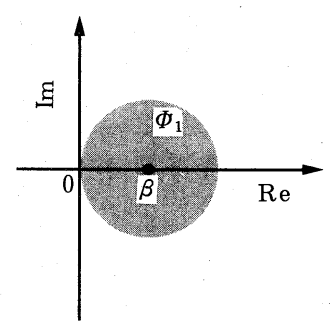

Fig. 2 Region of $\Phi_{1}$

補題 2 は基準モデル $G_{1}$ の右既約分解に基づく安定化 コントローラの表現を用いて導出した，同様の議論が $G_{2}$ の右既約分解に基づいても可能であるてとが明らかであ る. また, $G_{1}, G_{2}$ の左既約分解に基づく乙とも可能であ る. それらによって得られる安定化可能条件は等価では ない.

\section{2 補間コントローラによる安定条件}

つぎに，(3)，(4) 式の補間制御対象に対して，(5), (6) 式の補間コントローラによって制御系を安定化する 問題を考える. $\alpha=1$ のとき制御対象は $G=G_{1}$ でコン トローラは $K=K_{1}, \alpha=0$ のとき制御対象は $G=G_{2}$ で コントローラは $K=K_{2}$ となることより, $K_{1}, K_{2}$ はそ れぞれ基準モデル $G_{1}, G_{2}$ の安定化コントローラとなっ ていることが必要である. そてで, $K_{i}(i=1,2)$ を $G_{i}$ に対する安定化コントローラの一般形8)

$$
\begin{aligned}
& K_{i}=\tilde{D}_{K i}^{-1} \tilde{N}_{K i} \\
& \tilde{N}_{K i}=X_{i}+R_{i} \tilde{D}_{i} \\
& \tilde{D}_{K i}=Y_{i}-R_{i} \tilde{N}_{i}
\end{aligned}
$$

を用いて表現しておてう。ただし， $R_{i}$ は任意の $R H^{\infty}$ 
の元である.

補間コントローラで制御系を安定化する場合，任意の $K_{1}, K_{2}$ を補間したのでは，一般に制御系の安定性は保 証されない. 問題は $\alpha$ が 0 から 1 の間のいかなる值を とっても制御系が安定となるような補間コントローラ $K$ を構成する $K_{1}, K_{2}$ の求め方を明らかにすることである.

3.1 と同様, 制御系の安定条件, $\Omega_{2}=\tilde{D}_{K} D+\tilde{N}_{K} N$ がュニモジュラとなる条件を考える． $\Omega_{2}$ に (4)，(6) お よび（24）式を代入し，（9）式を利用するととにより，

$$
\begin{aligned}
& \Omega_{2}=\left(2 \alpha^{2}-2 \alpha+1\right) I+\alpha(1-\alpha) \Phi_{2} \\
&=\left\{2 \alpha^{2}-2 \alpha+1+\alpha(1-\alpha) \beta\right\} I \\
&+\alpha(1-\alpha)\left(\Phi_{2}-\beta I\right) \\
&=\alpha(1-\alpha)\left\{\frac{2 \alpha^{2}-2 \alpha+1+\alpha(1-\alpha) \beta}{\alpha(1-\alpha)} I\right. \\
&\left.+\left(\Phi_{2}-\beta I\right)\right\}
\end{aligned}
$$

と計算できる、ただし，

$$
\begin{aligned}
\Phi_{2} & =T_{a 2}-R_{12} T_{b 2} \\
T_{a 2} & =X_{1} N_{2}+Y_{1} D_{2}+X_{2} N_{1}+Y_{2} D_{1} \\
T_{b 2} & =\left[\begin{array}{l}
\tilde{N}_{1} D_{2}-\tilde{D}_{1} N_{2} \\
\tilde{N}_{2} D_{1}-\tilde{D}_{2} N_{1}
\end{array}\right] \\
R_{12} & =\left[\begin{array}{ll}
R_{1} & R_{2}
\end{array}\right]
\end{aligned}
$$

であり, $\beta$ は任意の正数である.

3.1 と同様汇補題 1 を用いると,

$$
\left\|\Phi_{2}-\beta I\right\|_{\infty}<\frac{2 \alpha^{2}-2 \alpha+1}{\alpha(1-\alpha)}+\beta
$$

であれば， $\Omega_{2}$ がユニモジュラとなり，制御系が安定と なることがいえる.（29）式の右辺は， $\alpha=1 / 2$ で最小値 $2+\beta$ をとるので,

$$
\left\|\Phi_{2}-\beta I\right\|_{\infty}<2+\beta
$$

であれば， $\alpha$ の值によらず $\Omega_{2}$ がユニモジュラとなる.

以上より, 次の補題が成り立ち, 補間コントローラの 存在条件が $H^{\infty}$ 制御問題の可解性汇帰着される.

【補題 3a】 ある正数 $\beta$ に対して,

$$
\left\|\left(T_{a 2}-\beta I\right)-R_{12} T_{b 2}\right\|_{\infty}<2+\beta
$$

を満たす $R_{12} \in R H^{\infty}$ が存在すれば補間制御対象 $G$ を 安定化する補間コントローラ $K$ が存在する.

（注意 3 ） 補題 2 亿対する注意 2 で述べたのと同じ理 由により，(31）式の条件は， $\beta$ を大きく選ぶほど成立し やすい. 制御対象が 1 入力 1 出力の場合, 乙の条件は, 右閉半平面の $s$ に対する (25) 式の $\Phi_{2}$ の值が Fig. 3

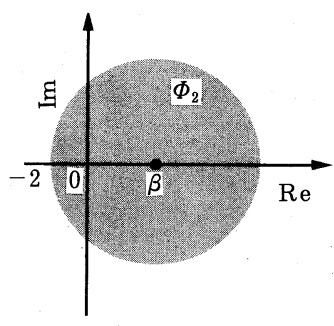

Fig. 3 Region of $\Phi_{2}$

の冈の内部に入るととを意味する.な扔，1入力 1 出力 の制御対象の場合の必要十分条件 ${ }^{5), 6)}$ は，右閉半平面の $s$ 亿対する $\Phi_{2}$ の值が実軸の $(-\infty,-2]$ を除く領域内に 存在することである.

補間制御対象を，基準モデルの左既約分解を用いて

$$
\begin{aligned}
& G=\tilde{D}^{-1} \tilde{N} \\
& \tilde{N}=\alpha \tilde{N}_{1}+(1-\alpha) \tilde{N}_{2}, \\
& \tilde{D}=\alpha \tilde{D}_{1}+(1-\alpha) \tilde{D}_{2}, \\
& \quad 0 \leq \alpha \leq 1
\end{aligned}
$$

によって記述し，補間コントローラを

$$
\begin{aligned}
K= & N_{K} D_{K}^{-1} \\
N_{K}= & \alpha N_{K 1}+(1-\alpha) N_{K 2} \\
D_{K}= & \alpha D_{K 1}+(1-\alpha) D_{K 2} \\
N_{K i}= & \tilde{X}_{i}+D_{i} Q_{i}, \\
D_{K i}= & \tilde{Y}_{i}-N_{i} Q_{i}, \\
& Q_{i} \in R H^{\infty}, \quad i=1,2
\end{aligned}
$$

と定義したとき, 補題 $3 \mathrm{a}$ と同様の条件がつぎのように 得られる. てれは, 一般に, 補題 $3 \mathbf{a}$ と等価ではない.

【補題 $3 \mathrm{~b}$ ある正数 $\beta$ 亿対して

$$
\left\|\left(V_{a 2}-\beta I\right)-V_{b 2} Q_{12}\right\|_{\infty}<2+\beta
$$

を満たす $Q_{12} \in R H^{\infty}$ が存在すれば，補間制御対象を安 定化する補間コントローラ $K$ が存在する. ただし，

$$
\begin{aligned}
& V_{a 2}=\tilde{N}_{1} \tilde{X}_{2}+\tilde{D}_{1} \tilde{Y}_{2}+\tilde{N}_{2} \tilde{X}_{1}+\tilde{D}_{2} \tilde{Y}_{1} \\
& V_{b 2}=\left[\begin{array}{ll}
\tilde{D}_{2} N_{1}-\tilde{N}_{2} D_{1} & \tilde{D}_{1} N_{2}-\tilde{N}_{1} D_{2}
\end{array}\right] \\
& Q_{12}=\left[\begin{array}{ll}
Q_{1}^{\mathrm{T}} & Q_{2}^{\mathrm{T}}
\end{array}\right]^{\mathrm{T}}
\end{aligned}
$$

である.

\section{4. 状態空間でのコントローラの導出}

3.に沶いて, 補間制御対象を安定化するコントローラ の設計問題が $H^{\infty}$ 制御問題に帰着された。 乙の問題を 解く方法として，ロバスト安定化問題9) と同様に， $s$ 領 
域の有理関数行列の補間極值問題として定式化すること が考えられる. しかし，ロバスト安定化問題の場合とは, 現れる有理関数行列の大きさやプロパ性が異なるため, その定式化では求解が不可能であったり, 可能であ議論 が非常に煩わしくなる.

そこで, 本節では, 状態空間でての $H^{\infty}$ 制御問題を 解く方法を与える. 乙の方法によれば, コントローラの 設計を直接行うことができる. 簡単のため, 基準モデル $G_{i}(i=1,2)$ の既約分解はつぎの状態空間表現 ${ }^{10)}$ で与 えられているあのとする. すなわち, $m$ 入力 $p$ 出力の 基準モデル $G_{i}(i=1,2)$ の最小実現

$$
G_{i}=C_{i}\left(s I-A_{i}\right)^{-1} B_{i}=\left[\begin{array}{c|c}
A_{i} & B_{i} \\
\hline C_{i} & 0
\end{array}\right]
$$

に対し，(9) 式を満たす既約分解の各要素は,

$$
\begin{array}{ll}
N_{i}=\left[\begin{array}{c|c}
A_{F i} & B_{i} \\
\hline C_{i} & 0
\end{array}\right], \quad D_{i}=\left[\begin{array}{c|c}
A_{F i} & B_{i} \\
\hline-F_{i} & I
\end{array}\right] \\
X_{i}=\left[\begin{array}{c|c}
A_{L i} & L_{i} \\
\hline F_{i} & 0
\end{array}\right], \quad Y_{i}=\left[\begin{array}{c|c}
A_{L i} & B_{i} \\
\hline F_{i} & I
\end{array}\right] \\
\tilde{N}_{i}=\left[\begin{array}{c|c}
A_{L i} & B_{i} \\
\hline C_{i} & 0
\end{array}\right], \quad \tilde{D}_{i}=\left[\begin{array}{c|c}
A_{L i} & L_{i} \\
\hline-C_{i} & I
\end{array}\right] \\
\tilde{X}_{i}=\left[\begin{array}{c|c}
A_{F i} & L_{i} \\
\hline F_{i} & 0
\end{array}\right], \quad \tilde{Y}_{i}=\left[\begin{array}{c|c}
A_{F i} & L_{i} \\
\hline C_{i} & I
\end{array}\right]
\end{array}
$$

によって与えられるとする.ただし，

$$
A_{F i} \triangleq A_{i}-B_{i} F_{i}, A_{L i} \triangleq A_{i}-L_{i} C_{i}
$$

であり， $F_{i}, L_{i}$ は，それぞれ上の $A_{F i}, A_{L i}$ を安定化す る任意の行列である.

\section{$4.1 H^{\infty}$ 制御問題の解}

まず，準備として一つの $H^{\infty}$ 制御問題の解を示してお く.これは参考文献 11)，12）の結果を組み合わせるて とによって得られる.

【補題 4】伝達関数行列 $T_{a}$ ( $h$ 入力 $h$ 出力), $T_{b}$ （ $h$ 入力 $q$ 出力）が, $n$ 次の状態空間表現

$$
\left[\begin{array}{c|c}
T_{a}-\delta I \\
T_{b}
\end{array}\right]=\left[\begin{array}{c|c}
A_{\#} & B_{\# 1} \\
\hline C_{\# 1} & (\xi-\delta) I_{h} \\
C_{\# 2} & 0_{(q \times h)}
\end{array}\right]
$$

によって表わされるとき(ただし， $T_{a}(\infty)=\xi I_{h}$ として (る),

$$
\left\|\left(T_{a}-\delta I\right)-R T_{b}\right\|_{\infty}<\gamma
$$

を満たす $R \in R H^{\infty}$ が存在するための必要十分条件は，
Riccati 方程式

$$
\begin{aligned}
& P\left(A_{\sharp}+\frac{\xi-\delta}{\gamma^{2}} B_{\sharp 1} C_{\sharp 1}\right)^{\mathrm{T}}+\left(A_{\sharp}+\frac{\xi-\delta}{\gamma^{2}} B_{\sharp 1} C_{\sharp 1}\right) P \\
& -\frac{1}{\gamma^{2}} P\left(\frac{\gamma^{2}}{\varepsilon} C_{\sharp 2}^{\mathrm{T}} C_{\# 2}-C_{\sharp 1}^{\mathrm{T}} C_{\# 1}-\frac{(\xi-\delta)^{2}}{\gamma^{2}} C_{\sharp 1}^{\mathrm{T}} C_{\# 1}\right) P \\
& +B_{\sharp 1} B_{\sharp 1}^{\mathrm{T}}+\varepsilon I=0
\end{aligned}
$$

に拉いて,

$$
\begin{aligned}
A_{s}= & A_{\sharp}+\frac{\xi-\delta}{\gamma^{2}} B_{\sharp 1} C_{\# 1} \\
& -\frac{1}{\gamma^{2}} P\left(\frac{\gamma^{2}}{\varepsilon} C_{\# 2}^{\mathrm{T}} C_{\# 2}-C_{\# 1}^{\mathrm{T}} C_{\# 1}-\frac{(\xi-\delta)^{2}}{\gamma^{2}} C_{\# 1}^{\mathrm{T}} C_{\# 1}\right)
\end{aligned}
$$

を安定にするような半正定解 $P$ が存在するてとである. ただし， $\varepsilon$ は十分小さな正の実数である.

このとき，(48）式を満たす $R$ は,

$$
R=\operatorname{DHM}(\Pi ; U), \quad \forall U \in B H^{\infty}
$$

と表わされる.ただし，

$$
\Pi=D_{\pi}^{\mathrm{T}}\left[\begin{array}{c|cc}
A_{s} & B_{\pi 1} & \frac{1}{\varepsilon} P C_{\# 2}^{\mathrm{T}} \\
\hline C_{\sharp 1} & I_{h} & 0_{h \times q} \\
0_{(h+n) \times n} & 0_{(h+n) \times h} & 0_{(h+n) \times q} \\
\frac{\gamma}{\sqrt{\varepsilon}} \mathrm{C}_{\# 2} & 0_{q \times h} & -\frac{\gamma}{\sqrt{\varepsilon}} I_{q}
\end{array}\right]
$$

$$
B_{\pi 1}=\frac{1}{\gamma^{2}}\left((\xi-\delta) B_{\sharp 1}+\frac{(\xi-\delta)^{2}}{\gamma^{2}} P C_{\sharp 1}^{\mathrm{T}}+P C_{\sharp 1}^{\mathrm{T}}\right)
$$

であり, $D_{\pi}$ は

$$
J=\left[\begin{array}{cc}
I_{h} & 0 \\
0 & -I_{(h+n+q)}
\end{array}\right], D_{V}=\left[\begin{array}{cc}
\frac{\varepsilon-\delta}{\gamma} I_{h} & 0 \\
I_{h} & 0 \\
0 & I_{n} \\
0_{q \times h} & 0_{q \times n}
\end{array}\right]
$$

に対して,

$$
D_{\pi}^{\mathrm{T}} J\left[\begin{array}{ll}
D_{\pi} & D_{V}
\end{array}\right]=\left[\begin{array}{ll}
J & 0
\end{array}\right]
$$

を満たす任意の行列である.

\section{2 固定コントローラの導出}

本節では, 3. の補題を用いて, 状態空間表現による固 定コントローラが存在するための十分条件と, コントロ 一ラの設計法を示す.

（41）（46）式を用いると, 補題 2 亿扔ける（22）式の $T_{a 1}-\beta I, T_{b 1}$ の状態空間表現は，以下のように計算で きる. 


$$
\begin{aligned}
& {\left[\begin{array}{c}
T_{a 1}-\beta I \\
T_{b 1}
\end{array}\right]=\left[\begin{array}{c|c}
\hat{A} & \hat{B}_{1} \\
\hline \hat{C}_{1} & (1-\beta) I \\
\hat{C}_{2} & 0
\end{array}\right]} \\
& \hat{A}=\left[\begin{array}{cc}
A_{L 1} & -B_{1} F_{2}+L_{1} C_{2} \\
0 & A_{F 2}
\end{array}\right] \\
& \hat{B}_{1}=\left[\begin{array}{ll}
B_{1}^{\mathrm{T}} & B_{2}^{\mathrm{T}}
\end{array}\right]^{\mathrm{T}} \\
& \hat{C}_{1}=\left[\begin{array}{ll}
F_{1} & -F_{2}
\end{array}\right], \quad \hat{C}_{2}=\left[\begin{array}{ll}
C_{1} & -C_{2}
\end{array}\right]
\end{aligned}
$$

上記の $T_{a 1}-\beta I, T_{b 1}$ に対して，(22）式を満たす $R_{1}$ が存在するための必要十分条件は, 補題 4 より, Riccati 方程式

$$
\begin{aligned}
& P\left(\hat{A}+\frac{1-\beta}{\beta^{2}} \hat{B}_{1} \hat{C}_{1}\right)^{\mathrm{T}}+\left(\hat{A}+\frac{1-\beta}{\beta^{2}} \hat{B}_{1} \hat{C}_{1}\right) P \\
& -\frac{1}{\beta^{2}} P\left(\frac{\beta^{2}}{\varepsilon} \cdot \hat{C}_{2}^{\mathrm{T}} \hat{C}_{2}-\hat{C}_{1}^{\mathrm{T}} C_{1}-\frac{(1-\beta)^{2}}{\beta^{2}} \hat{C}_{1}^{\mathrm{T}} \hat{C}_{1}\right) P \\
& +\hat{B}_{1} \hat{B}_{1}^{\mathrm{T}}+\varepsilon I=0
\end{aligned}
$$

に捈いて,

$$
\begin{aligned}
\hat{A}_{s}= & \hat{A}+\frac{1-\beta}{\beta^{2}} \hat{B}_{1} \hat{C}_{1} \\
& -\frac{1}{\beta^{2}} P\left(\frac{\beta^{2}}{\varepsilon} \hat{C}_{2}^{\mathrm{T}} \hat{C}_{2}-\hat{C}_{1}^{\mathrm{T}} \hat{C}_{1}-\frac{(1-\beta)^{2}}{\beta^{2}} \hat{C}_{1}^{\mathrm{T}} \hat{C}_{1}\right)
\end{aligned}
$$

を安定にする半正定解 $P$ が存在するてとである. てれ が成り立つとき $R_{1}$ は以下のように表現できる.

$$
R_{1}=\operatorname{DHM}\left(\Pi_{1} ; U_{1}\right), \quad \forall U_{1} \in B H^{\infty}
$$
ただし，

$$
\Pi_{1}=D_{\pi 1}^{\mathrm{T}}\left[\begin{array}{c|cc}
\hat{A}_{s} & \hat{B}_{\pi 1} & \frac{1}{\varepsilon} P \hat{C}_{2}^{\mathrm{T}} \\
\hline \hat{C}_{1} & I_{m} & 0_{m \times p} \\
0_{(m+n) \times n} & 0_{(m+n) \times m} & 0_{(m+n) \times p} \\
\frac{\beta}{\sqrt{\varepsilon}} \hat{C}_{2} & 0_{p \times m} & -\frac{\beta}{\sqrt{\varepsilon}} I_{p}
\end{array}\right]
$$

である.ただし，

$$
\hat{B}_{\pi 1}=\frac{1}{\beta^{2}}\left((1-\beta) \hat{B}_{1}+\frac{(1-\beta)^{2}}{\beta^{2}} P \hat{C}_{1}^{\mathrm{T}}+P \hat{C}_{1}^{\mathrm{T}}\right)
$$

であり, $D_{\pi 1}$ は

$$
J_{1}=\left[\begin{array}{cc}
I_{m} & 0 \\
0 & -I_{(m+n+p)}
\end{array}\right], D_{V 1}=\left[\begin{array}{cc}
\frac{1-\beta}{\beta} I_{m} & 0 \\
I_{m} & 0 \\
0 & I_{n} \\
0_{p \times m} & 0_{p \times n}
\end{array}\right]
$$

に対して,

$$
D_{\pi 1}^{\mathrm{T}} J_{1}\left[\begin{array}{ll}
D_{\pi 1} & D_{V 1}
\end{array}\right]=\left[\begin{array}{ll}
J_{1} & 0
\end{array}\right]
$$

を満たす任意の行列である.

ところで，(13)，(14）式のコントローラは記号 DHM を用いると，

$$
\begin{aligned}
& K=\operatorname{DHM}\left(Z_{1} ; R_{1}\right), R_{1} \in R H^{\infty} \\
& Z_{1}=\left[\begin{array}{cc}
Y_{1} & X_{1} \\
-\tilde{N}_{1} & \tilde{D}_{1}
\end{array}\right]=\left[\begin{array}{c|cc}
A_{L 1} & B_{1} & L_{1} \\
\hline F_{1} & I & 0 \\
-C_{1} & 0 & I
\end{array}\right]
\end{aligned}
$$

と表現できる，(62）式に，(60) 式を代入し，(12）式を 利用すると，

$$
\begin{aligned}
K & =\operatorname{DHM}\left(Z_{1} ; R_{1}\right) \\
& =\operatorname{DHM}\left\{Z_{1} ; \operatorname{DHM}\left(\Pi_{1} ; U_{1}\right)\right\} \\
& =\operatorname{DHM}\left(\Pi_{1} Z_{1} ; U_{1}\right)
\end{aligned}
$$

と変形できる．よって， $\hat{K} \triangleq \Pi_{1} Z_{1}$ を計算すればよい．

(61), (63) 式加 $\Pi_{1} Z_{1}$ を計算し，不可制御，不可観 測部分を取り除くことにより，

$$
\hat{K}=D_{\pi 1}^{\mathrm{T}}\left[\begin{array}{c|cc}
\hat{A}_{s} & B_{\hat{K} 1} & B_{\hat{K} 2} \\
\hline \hat{C}_{1} & I_{m} & 0_{(m \times p)} \\
0_{(m+n) \times n} & 0_{(m+n) \times m} & 0_{(m+n) \times p} \\
\frac{\beta}{\sqrt{\varepsilon}} \hat{C}_{2} & 0_{(p \times m)} & -\frac{\beta}{\sqrt{\varepsilon}} I_{p}
\end{array}\right]
$$

を得る.ただし，

$$
\begin{aligned}
& B_{\hat{K} 1}=\hat{B}_{\pi 1}+\left[\begin{array}{ll}
B_{1}^{\mathrm{T}} & 0
\end{array}\right]^{\mathrm{T}} \\
& B_{\hat{K} 2}=\frac{1}{\varepsilon} P \hat{C}_{2}^{\mathrm{T}}+\left[\begin{array}{ll}
L_{1}^{\mathrm{T}} & 0
\end{array}\right]^{\mathrm{T}}
\end{aligned}
$$

である，以上より，次の定理が成り立つ。

【定理 1】ある正数 $\beta$ に対して，(58) 式の Riccati 方程式が (59) 式を安定にする半正定解 $P$ をあつならば, (3)，(4) 式の補間制御対象 $G$ に対して，固定コントロ - ラ

$$
K=\operatorname{DHM}\left(\hat{K} ; U_{1}\right), \quad \forall U_{1} \in B H^{\infty}
$$

は制御系を安定にする。

\section{3 補間コントローラの導出}

（41）（46）式を用いると, 補題 $3 \mathbf{a}$ の（31）式におけ る $T_{a 2}-\beta I, T_{b 2}$ は,

$$
\left[\begin{array}{c}
T_{a 2}-\beta I \\
T_{b 2}
\end{array}\right]=\left[\begin{array}{c|c}
\bar{A} & \bar{B}_{1} \\
\hline \bar{C}_{1} & (2-\beta) I \\
\bar{C}_{2} & 0
\end{array}\right]
$$


と表わされる. ただし，

$$
\begin{aligned}
\bar{A} & =\left[\begin{array}{cccc}
A_{L 1} & -B_{1} F_{2}+L_{1} C_{2} & 0 & 0 \\
0 & A_{F 2} & 0 & 0 \\
0 & 0 & A_{L 2} & -B_{2} F_{1}+L_{2} C_{1} \\
0 & 0 & 0 & A_{F 1}
\end{array}\right] \\
\bar{B}_{1} & =\left[\begin{array}{llll}
B_{1}^{\mathrm{T}} & B_{2}^{\mathrm{T}} & B_{2}^{\mathrm{T}} & B_{1}^{\mathrm{T}}
\end{array}\right]^{\mathrm{T}} \\
\bar{C}_{1} & =\left[\begin{array}{llll}
F_{1} & -F_{2} & F_{2} & -F_{1}
\end{array}\right] \\
\bar{C}_{2} & =\left[\begin{array}{cccc}
C_{1} & -C_{2} & 0 & 0 \\
0 & 0 & C_{2} & -C_{1}
\end{array}\right]
\end{aligned}
$$

である.上記の $T_{a 2}-\beta I, T_{b 2}$ に対して，(31）式を満 たす $R_{12}$ が存在するための必要十分条件は, 補題 4 より Riccati 方程式

$$
\begin{gathered}
P\left(\bar{A}+\frac{2-\beta}{(2+\beta)^{2}} \bar{B}_{1} \bar{C}_{1}\right)^{\mathrm{T}}+\left(\bar{A}+\frac{2-\beta}{(2+\beta)^{2}} \bar{B}_{1} \bar{C}_{1}\right) P \\
-\frac{1}{(2+\beta)^{2}} P\left(\frac{(2+\beta)^{2}}{\varepsilon} \bar{C}_{2}^{\mathrm{T}} \bar{C}_{2}-\bar{C}_{1}^{\mathrm{T}} \bar{C}_{1}\right. \\
\left.-\frac{(2-\beta)^{2}}{(2+\beta)^{2}} \bar{C}_{1}^{\mathrm{T}} \bar{C}_{1}\right) P+\bar{B}_{1} \bar{B}_{1}^{\mathrm{T}}+\varepsilon I=0
\end{gathered}
$$

に扔いて

$$
\begin{aligned}
\bar{A}_{s}= & \bar{A}+\frac{2-\beta}{(2+\beta)^{2}} \bar{B}_{1} \bar{C}_{1}-\frac{1}{(2+\beta)^{2}} P \\
& \times\left(\frac{(2+\beta)^{2}}{\varepsilon} \bar{C}_{2}^{\mathrm{T}} \bar{C}_{2}-\bar{C}_{1}^{\mathrm{T}} \bar{C}_{1}-\frac{(2-\beta)^{2}}{(2+\beta)^{2}} \bar{C}_{1}^{\mathrm{T}} \bar{C}_{1}\right)
\end{aligned}
$$

を安定にする半正定解 $P$ が存在することである. との とき， $R_{12}$ は以下のように表わされる.

$$
R_{12}=\operatorname{DHM}\left(\Pi_{2} ; U_{2}\right), \quad \forall U_{2} \in B H^{\infty}
$$
ただし，

$$
\Pi_{2}=D_{\pi 2}^{\mathrm{T}}\left[\begin{array}{c|cc}
\bar{A}_{s} & \bar{B}_{\pi 1} & \frac{1}{\varepsilon} P \bar{C}_{2}^{\mathrm{T}} \\
\hline \bar{C}_{1} & I_{m} & 0_{m \times 2 p} \\
0_{(m+n) \times n} & 0_{(m+n) \times m} & 0_{(m+n) \times 2 p} \\
\frac{2+\beta}{\sqrt{\varepsilon}} \bar{C}_{2} & 0_{2 p \times m} & -\frac{2+\beta}{\sqrt{\varepsilon}} I_{2 p}
\end{array}\right],
$$

$$
\bar{B}_{\pi 1}=\frac{1}{(2+\beta)^{2}}\left((2-\beta) \bar{B}_{1}+\frac{(2-\beta)^{2}}{(2+\beta)^{2}} P \bar{C}_{1}^{\mathrm{T}}+P \bar{C}_{1}^{\mathrm{T}}\right)
$$

であり, $D_{\pi 2}$ は

$$
J_{2}=\left[\begin{array}{cc}
I_{m} & 0 \\
0 & -I_{(m+n+2 p)}
\end{array}\right], D_{V 2}=\left[\begin{array}{cc}
\frac{2-\beta}{(2+\beta)} I_{m} & 0 \\
I_{m} & 0 \\
0 & I_{n} \\
0_{2 p \times m} & 0_{2 p \times n}
\end{array}\right]
$$

に対して,

$$
D_{\pi 2}^{\mathrm{T}} J_{2}\left[\begin{array}{ll}
D_{\pi 2} & D_{V 2}
\end{array}\right]=\left[\begin{array}{ll}
J_{2} & 0
\end{array}\right]
$$

を満たす任意の行列である.

さて，(5)，(6) 式扔よび（24）式によって表わされる 補間コントローラは DHM を用い机ば,

$$
K=\operatorname{DHM}\left\{Z_{a} ;\left[\begin{array}{ll}
R_{1} & R_{2}
\end{array}\right]\right\},\left[\begin{array}{ll}
R_{1} & R_{2}
\end{array}\right] \in R H^{\infty}
$$

$$
Z_{\alpha}=\left[\begin{array}{cc}
\alpha Y_{1}+(1-\alpha) Y_{2} & \alpha X_{1}+(1-\alpha) X_{2} \\
{\left[\begin{array}{c}
-\alpha \tilde{N}_{1} \\
-(1-\alpha) \tilde{N}_{2}
\end{array}\right]} & {\left[\begin{array}{c}
\alpha \tilde{D}_{1} \\
(1-\alpha) \tilde{D}_{2}
\end{array}\right]}
\end{array}\right]
$$

$$
=\left[\begin{array}{cc|cc}
A_{L 1} & 0 & \alpha B_{1} & \alpha L_{1} \\
0 & A_{L 2} & (1-\alpha) B_{2} & (1-\alpha) L_{2} \\
\hline F_{1} & F_{2} & I_{m} & 0_{m \times p} \\
-C_{1} & 0 & 0_{p \times m} & \alpha I_{p} \\
0 & -C_{2} & 0_{p \times m} & (1-\alpha) I_{p}
\end{array}\right]
$$

と表現できる.

4.2 と同様, (72) 式に（70）式を代入すると,

$$
\begin{aligned}
K & =\operatorname{DHM}\left(Z_{\alpha} ; R_{12}\right) \\
& =\operatorname{DHM}\left\{Z_{\alpha} ; \operatorname{DHM}\left(\Pi_{2} ; U_{2}\right)\right\} \\
& =\operatorname{DHM}\left(\Pi_{2} Z_{a} ; U_{2}\right)
\end{aligned}
$$

と変形できるので, $\bar{K} \triangleq \Pi_{2} Z_{a}$ を計算すればよい. (71), （73）式を用いて， $\bar{K}=\Pi_{2} Z_{a}$ を計算し，不可制御，不 可観測部分を取り除くことにより,

$$
\bar{K}=D_{\pi 2}^{\mathrm{T}}\left[\begin{array}{c|cc}
\bar{A}_{s} & B_{\bar{K} 1} & B_{\bar{K} 2} \\
\hline \bar{C}_{1} & I_{m} & 0_{(m \times p)} \\
0_{(m+n) \times n} & 0_{(m+n) \times m} & 0_{(m+n) \times p} \\
\frac{2+\beta}{\sqrt{\varepsilon}} \bar{C}_{2} & 0_{(2 p \times m)} & D_{\bar{K} 22}
\end{array}\right]
$$

を得る.ただし，

$$
\begin{aligned}
& B_{\bar{K} 1}=\bar{B}_{\pi 1}+B_{\alpha}, \quad B_{\bar{K} 2}=\frac{1}{\varepsilon} P C_{\alpha}^{\mathrm{T}}+L_{\alpha} \\
& D_{\bar{K} 22}=-\frac{2+\beta}{\sqrt{\varepsilon}}\left[\begin{array}{c}
\alpha I_{p} \\
(1-\alpha) I_{p}
\end{array}\right] \\
& B_{\alpha}=\left[\begin{array}{llll}
\alpha B_{1}^{\mathrm{T}} & 0 & (1-\alpha) B_{2}^{\mathrm{T}} & 0
\end{array}\right]^{\mathrm{T}} \\
& C_{a}=\left[\begin{array}{llll}
\alpha C_{1} & -\alpha C_{2} & (1-\alpha) C_{2} & -(1-\alpha) C_{1}
\end{array}\right] \\
& L_{\alpha}=\left[\begin{array}{llll}
\alpha L_{1}^{\mathrm{T}} & 0 & (1-\alpha) L_{2}^{\mathrm{T}} & 0
\end{array}\right]
\end{aligned}
$$

である，以上より，つぎの定理が成り立つ. 
【定理 2】 ある正数 $\beta$ に対して，(68）式の Riccati 方 程式が (69) 式を安定にする半正定解 $P$ をあつとき, (3), (4) 式の補間制御対象 $G$ に対して, 補間コントローラ

$$
K=\operatorname{DHM}\left(\bar{K} ; U_{2}\right), \quad \forall U_{2} \in B H^{\infty}
$$

は制御系を安定化する.

（注意 4） 上記のコントローラに掠いて， $\alpha=1, \alpha=0$ とすれば，補間コントローラを構成する $K_{1}, K_{2}$ が得ら れることは明らかである.

\section{5. 同時安定化問題亡の関連}

固定コントローラによって補間制御対象を安定化する には, 二つの基準モデル $G_{1}, G_{2}$ が同時安定化可能であ ることが必要であることは明らかである。しかし補間 コントローラによって安定化する場合にはどうであろう か？筆者らは，すでに，制御対象が 1 入力 1 出力の場 合について, 同時安定化可能性の必要性を示している6 本節では, 多入力多出力の場合にあ必要であるととを示 す.

同時安定化問題に関しては, 次の補題”が知られてい る.

【補題 5】 $G_{1}, G_{2}$ は（9）式を満たす既約分解で (1), （2）式のように表わされるとする. そして,

$$
\begin{aligned}
& W_{a}=X_{1} N_{2}+Y_{1} D_{2} \\
& W_{b}=\tilde{D}_{1} N_{2}-\tilde{N}_{1} D_{2}
\end{aligned}
$$

とおいて, $W_{b}$ の実軸上（無限遠点も含む）の不安定な ブロッキング零点を

$$
0 \leq \sigma_{1}<\cdots<\sigma_{m}
$$

と定義する. 乙のとき, $G_{1}$ と $G_{2}$ が同時安定化可能であ る必要十分条件は, $\operatorname{det} W_{a}\left(\sigma_{i}\right), i=1, \cdots, m$ が一定符 号をとるととである.

この補題 5 を用いるととにより, 以下の命題が証明で きる.

【命題】（3），(4) 式で表わされる補間制御対象が安定 化可能であるためには， $G_{1}$ と $G_{2}$ が同時安定化可能であ ることが必要である.

（証明）まます，(77)，（78）式の $W_{a}, W_{b}$ の定義は，

$$
\left[\begin{array}{l}
W_{a} \\
W_{b}
\end{array}\right]=\left[\begin{array}{cc}
Y_{1} & X_{1} \\
-\tilde{N}_{1} & \tilde{D}_{1}
\end{array}\right]\left[\begin{array}{c}
D_{2} \\
N_{2}
\end{array}\right]
$$

と書ける。（9）式を考慮すると，

$$
\left[\begin{array}{cc}
Y_{1} & X_{1} \\
-\tilde{N}_{1} & \tilde{D}_{1}
\end{array}\right]^{-1}=\left[\begin{array}{cc}
D_{1} & -\tilde{X}_{1} \\
N_{1} & \tilde{Y}_{1}
\end{array}\right]
$$

であるので，(80) 式より,

$$
\left[\begin{array}{cc}
D_{1} & -\tilde{X}_{1} \\
N_{1} & \tilde{Y}_{1}
\end{array}\right]\left[\begin{array}{c}
W_{a} \\
W_{b}
\end{array}\right]=\left[\begin{array}{c}
D_{2} \\
N_{2}
\end{array}\right]
$$

が成り立つ。

いま, $G_{1}, G_{2}$ が同時安定化可能でないとしょう.乙 のとき補題 $\mathbf{5}$ より,

$$
\operatorname{det} W_{a}\left(\sigma_{j}\right)<0
$$

となる $j$ が存在する. $s=\sigma_{j}$ に拉いて, $W_{b}\left(\sigma_{j}\right)=0$ で あるので，(82）式より，

$$
\left[\begin{array}{l}
D_{1}\left(\sigma_{j}\right) \\
N_{1}\left(\sigma_{j}\right)
\end{array}\right] W_{a}\left(\sigma_{j}\right)=\left[\begin{array}{l}
D_{2}\left(\sigma_{j}\right) \\
N_{2}\left(\sigma_{j}\right)
\end{array}\right]
$$

が成り立つ。乙れを利用すると補間制御対象の表現にお ける(4) 式の $N, D$ 亿扔いて,

$$
\begin{aligned}
& N\left(\sigma_{j}\right)=N_{1}\left(\sigma_{j}\right)\left\{\alpha I+(1-\alpha) W_{a}\left(\sigma_{j}\right)\right\} \\
& D\left(\sigma_{j}\right)=D_{1}\left(\sigma_{j}\right)\left\{\alpha I+(1-\alpha) W_{a}\left(\sigma_{j}\right)\right\}
\end{aligned}
$$

が成り立つ.こてで補間制御対象の安定化可能性を考え るため,

$$
\Omega=\tilde{N}_{K} N+\tilde{D}_{K} D
$$

がユニモジュラとなるような $\tilde{N}_{K}, \tilde{D}_{K}$ の存在性を考え る. $s=\sigma_{j}$ における (86) 式に（85）式を代入すると,

$$
\begin{aligned}
\Omega\left(\sigma_{j}\right)= & \left\{\tilde{N}_{K}\left(\sigma_{j}\right) N_{1}\left(\sigma_{j}\right)+\tilde{D}_{K}\left(\sigma_{j}\right) D_{1}\left(\sigma_{j}\right)\right\} \\
& \times\left\{\alpha I+(1-\alpha) W_{a}\left(\sigma_{j}\right)\right\}
\end{aligned}
$$

となる。 $\alpha=0$ のとき，

$$
\operatorname{det}\left[\alpha I+(1-\alpha) W_{a}\left(\sigma_{j}\right)\right]=\operatorname{det} W_{a}\left(\sigma_{j}\right)<0
$$

$\alpha=1$ のとき,

$$
\operatorname{det}\left[\alpha I+(1-\alpha) W_{a}\left(\sigma_{j}\right)\right]=1>0
$$

なので,

$$
\operatorname{det}\left[\alpha_{0} I+\left(1-\alpha_{0}\right) W_{a}\left(\sigma_{j}\right)\right]=0
$$

となるような $\alpha_{0}$ が存在する．したがって $\alpha=\alpha_{0}$ におい て $\Omega$ をユニモジュラとするような $\tilde{N}_{K}, \tilde{D}_{K}$ は存在せず, 補間制御対象を安定化するコントローラは存在しない.

(証明終)

（注意 5 ）上記の証明は, 補間制御対象のみに着目し た，コントローラの構成に独立な議論である。したがっ て, 二つの基準モデルが同時安定化可能でない場合には, いかなるコントローラによっても既約分解の選び方によ らず補間制御対象は安定化できないことを意味する。

\section{6. おわりに}

多入力多出力の補間制御対象に対して, 制御系を安定 化する固定コントローラおよび補間コントローラが存在 するための十分条件を，ある $H^{\infty}$ 制御問題の可解性に帰 
着させ, 状態空間表現によるコントローラの設計法を示 した. そして，二つの基準モデルの同時安定化可能性が, 補間制御対象が安定化可能であるために必要であること を，多入力多出力系についてあ明らかにした.

本論文では，補間制御対象を時変系として記述してい ないので, 制御対象の变化の過渡状態に打ける挙動は考 察していない. しかし，動作状態が変化し制御対象の特 性が変化したとき，それぞれの定常状態においての制御 系の安定性が保証されるという意味で，実際の制御にお いても十分有効性をむつ.

なお，基準モデルの既約分解の選び方が異なれば，補 間によって表現された制御対象は異なる。そして，補間 制御対象の安定化可能性む既約分解の選び方に依存して いる.したがって，実際の制御系設計においては，どの ような既約分解の補間を用いるかが制御対象のモデリン グとの関連に㧠いて重要となる。

なお，本論文では基準モデルの数は 2 としたが，乙れ をn(>2) とした場合については，参考文献 13) に扔い て考察している.

\section{参 考 文 献}

1) T. Tanaka, Y. Aizawa and H. Eguchi : Multiple Operating Conditions Model and Design of Gain Scheduler ; 第 34 回自動制御連合講演会前刷, pp. 239〜242 (1991)

2) 山口, 田鍋, 村上, 後藤 : ファジー連想記憶システムを用 いた適応制御; 電気学会論文誌 (C), Vol. 111, No. 1, pp. 40 46 (1990)

3) 保田 : 構造的不確かさをあつシステムのロバスト安定化; 電 子情報通信学会論文誌 (A), Vol. J 75-A, No. 5, pp. 926〜 933 (1992)

4) B. K. Ghosh : An Approach to Simultaneous System Design, Part II : Nonswitching Gain and Dynamic Feedback Compensation by Algebraic Geometric Methods ; SIAM J. Control and Optimization, Vol. 26, No. 4, pp. 919 963 (1988)

5) Z. Chen, Y. Hayakawa and S. Fujii : On the Stabilizability of Plants with Variable Operating Conditions ; 第 22 回制御理論シンポジウム資料, pp. 55〜60 (1993)

6)村松, 池田：動作状態が変化する制御対象の安定化 ; 第 15 回 Dymamical System Theory シンポジゥム資料, pp. 53〜 56 (1992)

7) C. Abdallah, P. Dorato, F. Perez and D. Docampo: From Nyquist to Kharitonov: Synthesis of Robust Controllers ; Preprints of 12 th IFAC World Congress, Vol. I, pp. 41 44 (1993)

8）前田, 杉江：アドバンスト制御のためのシステム制御理論, 朝倉書店 (1990)

9) M. Vidyasagar and H. Kimura : Robust Controllers for Uncertain Linear Multivariable Systems; Automatica, Vol. 22, No. 1, pp. 85 94 (1986)
10) C. N. Nett, C. A. Jacobson and M. J. Balas : A Connection Between State-Space and Doubly Coprime Fractional Representations; IEEE Trans. Automatic Control, Vol. AC-29, No. 9, pp. 831 832 (1984)

11) 小出, 原 : 虚軸上に零点を有する $H^{\infty}$ 制御問題の解法 ; 第 13 回 Dynamical System Theory シンポジゥム資料, pp. $11 \sim 14$ (1991)

12) 村松, 細江 : $R H^{\infty}$ 標準問題の直接的解法 ; 第 19 回制御理 論シンポジゥム資料, pp.119〜124 (1990)

13）西野，池田，村松：動作状態が変化するプラントに対する 補間コントローラ; 第 15 回 Dynamical System Theory シ ンポジゥム資料，pp. 67〜 70 (1992) 